\title{
Diagnosis and screening of patients with hereditary angioedema in primary care
}

\author{
This article was published in the following Dove Press journal: \\ Therapeutics and Clinical Risk Management \\ 2 May 2016 \\ Number of times this article has been viewed
}

\author{
Maria Paula Henao' \\ Jennifer L Kraschnewski' \\ Theodore Kelbel ${ }^{2}$ \\ Timothy J Craig ${ }^{3}$ \\ 'Department of Medicine, ${ }^{2}$ Division of \\ Allergy and Immunology, ${ }^{3}$ Department \\ of Medicine and Pediatrics, \\ Pennsylvania State University College \\ of Medicine at Hershey Medical \\ Center, Hershey, PA, USA
}

\begin{abstract}
Hereditary angioedema (HAE) is a rare autosomal dominant disease that commonly manifests with episodes of cutaneous or submucosal angioedema and intense abdominal pain. The condition usually presents due to a deficiency of $\mathrm{C} 1$ esterase inhibitor (C1-INH) that leads to the overproduction of bradykinin, causing an abrupt increase in vascular permeability. A less-understood and less-common form of the disease presents with normal C1-INH levels. Symptoms of angioedema may be confused initially with mast cell-mediated angioedema, such as allergic reactions, and may perplex physicians when epinephrine, antihistamine, or glucocorticoid therapies do not provide relief. Similarly, abdominal attacks may lead to unnecessary surgeries or opiate dependence. All affected individuals are at risk for a life-threatening episode of laryngeal angioedema, which continues to be a source of fatalities due to asphyxiation. Unfortunately, the diagnosis is delayed on average by almost a decade due to a misunderstanding of symptoms and general lack of awareness of the disease. Once physicians suspect HAE, however, diagnostic methods are reliable and available at most laboratories, and include testing for $\mathrm{C} 4$, $\mathrm{C} 1-\mathrm{INH}$ protein, and $\mathrm{C} 1-\mathrm{INH}$ functional levels. In patients with HAE, management consists of acute treatment of an attack as well as possible short- or long-term prophylaxis. Plasma-derived C1-INH, ecallantide, icatibant, and recombinant human C1-INH are new treatments that have been shown to be safe and effective in the treatment of HAE attacks. The current understanding of HAE has greatly improved in recent decades, leading to growing awareness, new treatments, improved management strategies, and better outcomes for patients.
\end{abstract}

Keywords: hereditary angioedema, HAE, C1-INH, C1-INH deficiency, angioedema, abdominal pain

\section{Background}

The rapid swelling of subcutaneous or submucosal tissues was first described in modern medical terms as "angioneurotic edema" by Quincke in 1882, although the symptoms were recognizable and reported in a handful of contemporary case reports. ${ }^{1-4}$ Occurring in isolation, accompanied by urticaria, or as a component of anaphylaxis, angioedema today is understood as a self-limited, localized subcutaneous or submucosal swelling due to a temporary increase in vascular permeability caused by the release of vasoactive mediators. ${ }^{3}$ The condition can be divided into two general types: mast cell-mediated and bradykinin-mediated. ${ }^{5}$ The former type is more commonly reported, is often precipitated by a trigger such as an exposure to an allergen, and may be accompanied by observable signs and symptoms including urticaria, flushing, generalized pruritus, bronchospasm, throat tightness, or hypotension. ${ }^{3}$ Mast cell-mediated angioedema improves with antihistamine and glucocorticoid treatment in acute allergic situations, and may require epinephrine if anaphylaxis occurs. ${ }^{5}$

Only a few years after Quincke in 1886, Osler documented extensive family histories of symptomatic patients and first described the hereditary form of this condition
Correspondence: Timothy ] Craig Department of Medicine and Pediatrics, Pennsylvania State University College of Medicine at Hershey Medical Center, 500 University Drive, UPC II, Suite 1300, Hershey, PA 17033, USA

$\mathrm{Tel}+\mathrm{I} 7175316525$

Fax +I 7175315785

Email tcraig@hmc.psu.edu (c) (i) (5) 2016 Henao et al. This work is published and licensed by Dove Medical Press Limited. The full terms of this license are available at https://www.dovepress.com/terms.ph a for commercial use of this work, please see paragraphs 4.2 and 5 of our Terms (https://www.dovepress.com/terms.php). 
known as hereditary angioedema (HAE). ${ }^{2,4,6}$ In this article, we will examine the rare autosomal dominant condition of HAE, defined today by recurrent episodic events of bradykininmediated angioedema that do not present with significant wheals, urticaria, or other signs of allergic reaction and typically fail to improve with treatment of antihistamines, glucocorticoids, or epinephrine. ${ }^{3}$

\section{HAE due to $\mathrm{Cl}-\mathrm{INH}$ deficiency}

While angioedema was accurately described since the late 19th century, the pathophysiologic factors of HAE remained a mystery until the early 1960s when independent research identified the deficiency of $\mathrm{C} 1$ esterase inhibitor (C1-INH) as the underlying cause. ${ }^{3,7,8} \mathrm{~A}$ few years later, it was shown that a second form of the disease was characterized by a dysfunctional C1-INH protein. ${ }^{3,9}$ This new understanding of the biological basis of the disease led to the classification of HAE due to C1-INH deficiency into two distinct types: type I (HAE-1), with reduced $\mathrm{C} 1-\mathrm{INH}$ protein and $\mathrm{C} 1-\mathrm{INH}$ functional levels, and type II (HAE-2), with normal C1-INH protein levels but reduced $\mathrm{C} 1-\mathrm{INH}$ functional levels.

Following these discoveries, researchers identified the association of the deficiency of C1-INH with the superfamily of genes known as serine (or cysteine) peptidase inhibitors (SERPIN). ${ }^{10}$ Subsequent research pinpointed the origin of the deficiency within the SERPING1 gene. ${ }^{3,11} \mathrm{HAE}-1$ mutations may vary among family members and are known to be highly heterogeneous; missense, nonsense, deletion, or insertion mutations may occur throughout the SERPING1 gene. ${ }^{3}$ Currently, more than 450 different mutations throughout the gene have been reported. ${ }^{11}$ On the other hand, HAE-2 generally results from missense mutations involving the region of the gene at or near the active site on the reactive mobile loop. ${ }^{3}$

Until recently, the pathogenesis of edema in patients with C1-INH deficiency was highly debated between the role of either $\mathrm{C} 2$-kinin, generated through activation of the classic complement pathway, or bradykinin, generated through activation of the contact system., ${ }^{3,12}$ It is now unequivocally understood that the primary biological mediator of swelling in HAE due to C1-INH deficiency (HAE-1/2) is bradykinin. ${ }^{14,15}$

\section{HAE with normal $\mathrm{CI}-\mathrm{INH}$}

Independent reports documented in 2000 expanded the classification of HAE to include a third form of the disease, originally known as type 3 and linked to elevated estrogen levels, in which affected individuals have normal C1-INH protein and functional levels. ${ }^{16-18}$ Although contemporary research has revealed that an estimated $25 \%$ of patients with this third type of HAE have a significant mutation in factor XII, the pathophysiology of this subtype in other patients is not understood. ${ }^{3,16-24}$ A contemporary consensus report has called for the standardization of the nomenclature of HAE with normal C1-INH, which should be divided into two subtypes: factor XII mutations (HAE-FXII) and unknown causes (HAE-U). ${ }^{25,26}$ In contrast to HAE-1/2, the role of bradykinin is not well understood in HAE with normal C1-INH, although drugs that inhibit bradykinin generation or signaling have successfully treated symptomatic patients in various reports. ${ }^{3}$

\section{Current outlook}

The current understanding of HAE has greatly improved in recent decades, leading to growing awareness, improved management, and better outcomes..$^{5,14,25-36}$ Nevertheless, a diagnosis of HAE is delayed for an average of 8.5 years from the initial presentation of symptoms, although some studies suggest average delays in excess of 13-20 years. ${ }^{31,37-42}$ These delays are worrisome given the significant risk of lifethreatening laryngeal angioedema in affected individuals. One recent study of fatalities due to HAE identified a significantly higher mortality by asphyxiation in undiagnosed HAE patients. ${ }^{43}$

It is important to note that bradykinin-mediated angioedema may result from other etiologies that can be confused with HAE. An acquired form of C1-INH deficiency often presents in older patients with low levels of C4 and C1-INH protein and functional levels, along with low C1q plasma levels in most cases, which is inconsistent with HAE. This acquired C1-INH deficiency is typically linked to an underlying disease, most commonly a lymphoproliferative disorder. ${ }^{3}$ ACE-inhibitor users may also develop angioedema since the inhibition of the kinase ACE results in increased bradykinin levels. ACE-inhibitor-induced angioedema is a much more common cause of angioedema than either hereditary or acquired $\mathrm{C} 1-\mathrm{INH}$ deficiency despite occurring in only $0.2 \%-0.7 \%$ of patients taking ACE-inhibitors. ${ }^{3,23}$ Finally, an idiopathic angioedema has been described in patients with normal $\mathrm{C} 1-\mathrm{INH}$ functional levels, no family history, and no response to high-dose antihistamines; epidemiology and pathogenesis of this form of angioedema are not understood. ${ }^{3}$

\section{Epidemiology}

A precise prevalence of HAE is unknown, although studies place estimates around 1 in $30,000-80,000$ in the general 
population. ${ }^{3,30}$ In HAE-1/2, the disease displays an autosomal dominant pattern, with $50 \%$ of male and female children of parents with HAE being equally affected. ${ }^{3}$ Approximately $25 \%$ of HAE- $1 / 2$ cases are caused by a de novo mutation. ${ }^{3,11}$ HAE-1 is the most common form of the disease making up around $85 \%$ of known cases, while HAE- 2 accounts for the remaining $15 \%$ of $\mathrm{HAE}$ due to $\mathrm{C} 1-\mathrm{INH}$ deficiency. ${ }^{3}$ There are no significant differences in incidence of $\mathrm{C} 1$-INH deficiency by race or ethnicity, although one recent study suggested that affected individuals from Mainland China, Taiwan, and Japan may have lower frequencies of abdominal episodes than counterparts in Western countries., ${ }^{3,44}$

HAE with normal C1-INH (HAE-FXII and HAE-U) has been documented as autosomal dominant and accounts for a very small percentage of HAE patients, although no reliable estimates have been made regarding its overall prevalence or distribution. Women are predominantly affected by this type of HAE; a minority of males have been diagnosed and tend to present with less-severe symptoms. ${ }^{3}$ Unlike HAE due to C1-INH deficiency, the inheritance pattern of HAE with normal C1-INH shows a generally low penetrance with evidence of obligate asymptomatic carriers, particularly men. ${ }^{25}$

\section{Clinical presentation}

Patients with HAE present with one or more of the following hallmark indicators:

1. Recurrent angioedema, most frequently on the extremities and face, affects nearly all individuals with HAE.

2. Intermittent abdominal pain is present in as many as $93 \%$ of patients. ${ }^{45}$

3. Approximately $75 \%$ of patients have a positive family history of similar symptoms, although the remaining cases result from a de novo mutation. ${ }^{3}$

\section{Recurrent angioedema}

Most angioedema events are episodic, with a gradual but relentless onset that worsens over the first 12-24 hours and slowly resolves within 2-5 days. ${ }^{3,39,46}$ Swelling episodes, which may vary greatly, are unpredictable, focal, and may occur at different locations simultaneously, but are not typically systemic. ${ }^{46,47}$ Cutaneous angioedema may occur independently or concurrently with abdominal pain. The angioedema associated with HAE is indistinguishable among types of the disease and is identical to the edema from reactions that are mast cell-mediated, with the skin described as nonpitting, not erythematous, nonpruritic, and with illdefined margins. It should be reiterated, however, that HAE patients do not present with urticaria, the presence of which virtually excludes a diagnosis of HAE.

In a large retrospective study, almost all patients with HAE experienced some form of skin swelling episodes, and around $90 \%$ of these episodes occurred in the extremities. ${ }^{45}$ Nearly eight out of ten patients experienced an episode of facial angioedema, although these episodes only accounted for approximately $3 \%$ of the total number of angioedema events. ${ }^{45}$ Similarly, genital swelling and other skin swelling occurred in over two-thirds of patients, but only accounted for approximately $4 \%$ of the total number of episodes. ${ }^{45}$ Less than $1 \%$ of the total number of reported angioedema episodes involved the larynx, tongue, uvula, soft palate, bladder, urethra, chest, kidneys, esophagus, and central nervous system, with some patients reporting bouts of migraine-like headaches. ${ }^{45}$

Episodes of laryngeal angioedema, cautiously understood as the exclusive cause of death directly attributable to HAE, should be treated immediately given the risk of asphyxiation. ${ }^{43}$ Whereas acute allergic reactions or anaphylaxis tend to peak within minutes of exposure, laryngeal edema in HAE patients takes place, on average, over the course of several hours, although some patients may undergo rapid episodes that transpire in less than 20 minutes. ${ }^{43}$ One retrospective study of 209 patients with HAE-1/2 revealed that around half of patients experience multiple laryngeal edema episodes in their lifetime, although these life-threatening events only accounted for $0.9 \%$ of the total number of angioedema events reported. ${ }^{45,48}$ In this study, $28.5 \%$ of the total facial angioedema episodes extended to laryngeal edema. ${ }^{45}$ While in the past up to $30 \%$ of patients with HAE are thought to have died due to asphyxiation, the improvement of management has greatly reduced the number of fatalities today, most of which occur in undiagnosed individuals. . $3,48,49$

\section{Abdominal pain}

The intense abdominal pain that occurs in up to $93 \%$ of patients is often confused with an acute surgical abdomen. ${ }^{45}$ Misunderstanding the severe pain leads to unnecessary exploratory laparotomies, appendectomies, or other invasive procedures, and a previous report indicates that as many as one-third of patients undergo abdominal operations before being diagnosed with HAE. ${ }^{32,38,40,50-52}$ Abdominal attacks typically last between 2 and 4 days. ${ }^{38,40}$ These episodes are often detrimental to an individual's productivity, and they may provoke opiate dependence and excessive absenteeism. ${ }^{40}$ Besides pain, gastrointestinal symptoms of HAE may include nausea, vomiting, and diarrhea. In at least some cases, these 
symptoms can lead to hypovolemic shock, ascites, and, in rare cases, circulatory collapse, tetany, hemorrhagic stools, dysuria, and intussusception of the colon. ${ }^{38,53,54}$

\section{Age at initial symptoms}

In about one-third of HAE-1/2 patients, clinical symptoms first present by age 5 , and these patients tend to have more severe outcomes than patients whose symptoms begin later in life. ${ }^{40,45,55}$ The majority of cases present before 20 years of age, while only approximately $4 \%$ of patients experience the first attack after age $40 .{ }^{40,45}$ The age of onset of symptoms may help a physician distinguish HAE from acquired C1-INH deficiency, which typically occurs in older patients.

\section{Triggers to symptoms}

Local trauma, infections, and emotional stress may trigger episodes of angioedema in patients with HAE; however, most attacks are not preceded by an identified trigger. Menstruation and initiation of oral contraceptives may be the main trigger in HAE patients with normal C1-INH. ${ }^{14,27,32,40,50,54,56}$ Some common causes of laryngeal or buccal angioedema include oropharyngeal procedures and dental surgeries. ${ }^{27}$ Prodromal symptoms prior to angioedema flares include fatigue, rashes such as erythema marginatum, joint or muscle pain, upset stomach/nausea, and numbness/tingling in the area of the attack. ${ }^{57}$ Although it has only recently begun to be documented in detail, many patients with HAE suffer psychological symptoms of depression and anxiety, which in turn may exacerbate outcomes. ${ }^{57-60}$ Due to the prevalence of these symptoms, it is thought that Quincke suspected this condition to be in part "neurotic", leading him to label the disease originally as "angioneurotic" edema. In recent decades, this label has fallen out of usage as the pathogenesis has become better understood. ${ }^{6}$

\section{Diagnosis and screening}

The most remarkable hurdle in contemporary diagnosis of HAE is the initial suspicion by the primary care or emergency physician given the low prevalence of the disease and the nonspecific symptoms, particularly during attacks of abdominal pain. As noted above, diagnosis of HAE is delayed for an average of 8.5 years from the initial presentation of symptoms. ${ }^{31,37-42}$ Long delays in diagnosis may be further complicated by unnecessary surgical interventions, psychological symptoms, opiate dependence, or life-threatening laryngeal angioedema. ${ }^{38,40,50,58-60}$ Once a clinician suspects HAE, however, laboratory tests and medical management can reliably confirm or exclude the diagnosis of C1-INHdeficient HAE. On the contrary, HAE with normal C1-INH remains a more challenging diagnosis.

\section{Clinical criteria for diagnosis}

A complete physical examination along with a detailed family history is the best way to raise suspicion of HAE in the primary care clinic. Questioning should attempt to recognize the typical history of recurrent attacks of angioedema (without urticaria), abdominal pain, family history of similar symptoms, association of attacks with stress or menses, and exacerbation of attacks after administration of estrogens or ACE-inhibitors (Table 1). ${ }^{51}$ It is important to distinguish HAE from other forms of angioedema, particularly mast cell-mediated reactions, which are much more common and resolve with epinephrine, antihistamine, and glucocorticoid treatment.

Table I Diagnosis of HAE due to $\mathrm{CI}-\mathrm{INH}$ deficiency (HAE-I/2)

\begin{tabular}{ll}
\hline Clinical features & Approximate percent (\%) affected \\
\hline Recurrent angioedema without wheals and without urticaria & $-100^{3}$ \\
Recurrent abdominal attacks & $93^{54}$ \\
Positive family history & $75^{3}$ \\
Occurrence of upper airway edema & $50^{43}$ \\
Presence of prodromal signs before episodes & $87-95.7^{57}$ \\
Failure to respond to antihistamines, glucocorticoid, or epinephrine & $\sim 100^{68}$ \\
Laboratory tests & Results \\
Serum C4 & Low (<50\% normal) \\
$\mathrm{Cl}-\mathrm{INH}$ protein & HAE-I: low $(<50 \%$ normal) \\
$\mathrm{Cl}-\mathrm{INH}$ function & HAE-2: normal or high \\
$\mathrm{Clq}$ & Low $(<50 \%$ normal) \\
\hline
\end{tabular}

Notes: aLaboratory tests should be repeated I-3 months later to confirm results; blood samples should be handled with care to avoid decay of functional $\mathrm{CI}-\mathrm{INH}$, which may produce equivocal results. ${ }^{5,75}$ bNinety percent of HAE patients have perpetually low C4; during acute attacks C4 is virtually always low. ${ }^{67,69}{ }^{\mathrm{c}} \mathrm{Acquired}$ angioedema due to $\mathrm{Cl}-\mathrm{INH}$ deficiency may result in low $\mathrm{Cl}$ q levels.

Abbreviations: $\mathrm{Cl}-\mathrm{INH}, \mathrm{Cl}$ esterase inhibitor; HAE, Hereditary angioedema. 


\section{Acute abdominal episodes and imaging tests}

If a patient is suffering from an abdominal episode of $\mathrm{HAE}$, diagnosis is challenging and often requires interdisciplinary collaboration and follow-up visits. The abdominal examination during acute attacks may be nonspecific with diffuse abdominal tenderness on palpation, hyper- or hypoactive bowel sounds, and shifting dullness if ascites is present. ${ }^{51}$ During an acute abdominal episode, patients may present with significant leukocytosis with neutrophilia along with increased levels of hematocrit while levels of C-reactive protein (CRP) remain low, although these findings are not common across all patients. . $9,61,62$

Imaging tests are generally not a useful diagnostic tool and are only helpful if taken during an acute episode; taken too early or too late, these tests will return falsenegative results. ${ }^{63}$ Subtle or mild intestinal edema may be overlooked on imaging even in symptomatic patients. ${ }^{64}$ As a result, negative scans do not necessarily exclude a diagnosis of HAE. Radiographs and conventional barium studies may demonstrate thumb printing due to bowel wall thickening in HAE, and bowel lumen narrowing or bowel distention can be present, although these scans may also display results nonspecific to angioedema..$^{52,63,64}$ The jejunum and duodenum are the most frequently affected bowel segments during an acute episode, with the colon, ileum, and stomach involved much less frequently. ${ }^{63}$ Contrast-enhanced CT scan may help exclude other causes of abdominal pain. ${ }^{63-65}$ Ultrasound may be used instead in pediatric patients to exclude other etiologies. ${ }^{63}$ Endoscopic procedures in HAE episodes have not been well described, and are generally discouraged since local trauma may induce a potentially life-threatening episode of laryngeal angioedema. ${ }^{48}$

\section{Laboratory tests}

The diagnosis of HAE should be confirmed through laboratory testing. ${ }^{26,39}$ Most patients with HAE due to C1-INH deficiency have persistently low antigenic C4 levels. ${ }^{26}$ During an acute angioedema attack virtually all patients with HAE have low C4 levels, with only one report (Karim et al) noting an exception. ${ }^{50,66-68}$ A measurement of $\mathrm{C} 4$ levels on asymptomatic patients has traditionally been considered a cost-effective screening test to rule out HAE, although in up to $10 \%$ of cases the $\mathrm{C} 4$ levels are normal. ${ }^{55,66,67,69,70}$ Therefore, a patient with low $\mathrm{C} 4$ levels should pursue further testing, while a normal or high $\mathrm{C} 4$ level is no longer recommended as a way to exclude a diagnosis of HAE. ${ }^{66,67,69}$
When low $\mathrm{C} 4$ levels are found in combination with low C1-INH function, the results had a $98 \%$ specificity for HAE due to C1-INH deficiency across a multicenter evaluation. ${ }^{67,70}$ Patients with HAE-1/2 usually do not consume $\mathrm{C} 1$ complex, and, as such, low C1q plasma levels suggest the distinct diagnosis of angioedema due to acquired C1-INH deficiency. ${ }^{5}$ Of note, cases of systemic or discoid lupus erythematosus associated with HAE have been described; in rare cases, patients may develop acquired C1-INH deficiency during systemic lupus with functional and quantitative C1-INH deficiency. ${ }^{71,72}$ When using the traditional assays, consensus recommendations dictate that laboratory tests be repeated 1-3 months later to confirm diagnosis. ${ }^{14,28,38,55,73,74}$ Blood samples should be handled with care to avoid decay of functional C1-INH, which may produce equivocal results. ${ }^{5,75}$

Two commercial assays are available to assess C1-INH levels using either a chromogenic assay or a complex ELISA. ${ }^{66,76}$ The chromogenic assay is generally considered preferable, with a positive predictive value approaching $100 \%$ despite occasional false positives, while the complex ELISA has a negative predictive value of only $62 \%{ }^{66,76}$ Using repeat tests improves the accuracy of the results. ${ }^{66,76}$ Current research has identified and developed two novel assays that show promise for future improvement in the diagnosis of HAE. ${ }^{66}$

\section{Genetic testing and screening of family members}

Although HAE is a genetic disease caused by a mutation usually affecting the SERPING1 gene (HAE-1/2) or factor XII (HAE-FXII), genetic testing can be costly, time-consuming, and rarely necessary. ${ }^{3}$ Importantly, a negative test result cannot be used to exclude the diagnosis because HAE is a highly heterogeneous genetic disease and new mutations that have not been previously identified are possible. ${ }^{31}$ Similarly, a positive test result may be consistent with the diagnosis but cannot predict the natural history of the disease because the same genotypes may have variable clinical presentations. ${ }^{31}$ Genetic testing may be useful, however, for pediatric patients under 1 year old when C1-INH plasma levels may be falsely low and to distinguish from acquired C1-INH deficiency later in life. ${ }^{26,28}$

Undiagnosed patients with HAE have an increased risk of death by asphyxiation compared to diagnosed individuals. ${ }^{43}$ Therefore, given that all types of HAE are autosomal dominant, testing of all first-degree family members is highly encouraged, although the practice is not yet common. ${ }^{27,30,31}$ 


\section{Criteria for diagnosis of $\mathrm{HAE}-\mathrm{I} / 2$}

To confirm a diagnosis of HAE, it is recommended that physicians work closely with an HAE expert. All patients suspected to have HAE due to C1-INH deficiency should be assessed for blood levels of serum C4, C1-INH protein, and C1-INH function. Results should be repeated within 1-3 months if $\mathrm{C} 4, \mathrm{C} 1-\mathrm{INH}$ protein, or C1-INH function are less than or near $50 \%$ normal. Given the distribution of HAE-2, approximately $15 \%$ of HAE patients are expected to have C1-INH protein levels within normal range or in some cases elevated levels. ${ }^{5}$ The World Allergy Organization (WAO) recommends a diagnosis be made in the presence of clinical symptoms as well as positive laboratory findings (Table 1$).^{5}$

\section{Diagnosis of HAE with normal $\mathrm{Cl}-\mathrm{INH}$ deficiency}

According to consensus guidelines, the diagnosis of HAE with normal C1-INH should only be made when patients meet a specific defined criteria (Table 2). ${ }^{5,25,26}$ Experts recognize that this definition represents the best currently available strategy for identifying HAE with normal C1-INH..$^{25}$ The laboratory diagnosis of HAE-FXII relies on genetic testing, while no confirmatory laboratory tests have been developed for HAE-U. ${ }^{5}$ Additionally, it is possible for some patients to experience de novo mutations or that other affected family members are asymptomatic because of the low penetrance of the disease. With continued research, experts are hopeful that additional laboratory or genetic markers will be found that will improve the ability to confirm the diagnosis. ${ }^{25}$ When suspicion of HAE-FXII and HAE-U is high based on clinical findings, it is recommended that physicians collaborate with an HAE specialist given the unique challenges to confirm diagnosis of HAE with normal C1-INH.

HAE with normal C1-INH significantly affects more females than males, and the initial appearance of symptoms does not typically occur before puberty, unlike in HAE-1/2. ${ }^{25}$ In addition, symptomatic episodes are generally less frequent in patients with $\mathrm{HAE}$ with normal $\mathrm{C} 1-\mathrm{INH}$, and these patients suffer from a higher percentage of facial and tongue swelling episodes, a lower percentage of abdominal episodes, and fewer multiorgan attacks. ${ }^{3,25}$

\section{Management}

In patients with HAE, management consists of either acute treatment of an attack or prophylaxis for future attack prevention. ${ }^{25,30,55}$ Given that all patients with HAE are at risk for a life-threatening attack regardless of the severity and location of prior episodes, all patients should have a management plan for dealing with acute angioedema attacks. ${ }^{27,55}$

\section{On-demand treatments}

Treatment of angioedema attacks is imperative to decrease morbidity and mortality. ${ }^{26,27,37,55}$ Early detection and treatment of an attack is beneficial as it allows for less fluid to move into the interstitium, therefore enabling faster recovery. ${ }^{55}$ Epinephrine may provide transient relief during acute attacks, but is not predictably reliable. ${ }^{55,68}$

International consensus recommends on-demand treatment be considered for all types of HAE attacks. $5,26,36,77,78$ Several medications are available for treatment of acute episodes of angioedema, however, availability varies throughout the world. ${ }^{27,30,77,79-81}$ Plasma-derived C1-INH (trade name Berinert [CSL Behring LLC, Kankakee, IL, USA] or Cinryze [ViroPharma Biologics, Inc., Exton, PA, USA]), ecallantide (trade name Kalbitor [Dyax Corporation, Burlington, MA, USA]), icatibant (trade name Firazyr [Shire Orphan Therapies, Inc., Lexington, MA, USA]), and recombinant human C1-INH (trade name Ruconest [Santarus Inc., Raleigh, NC, USA]) are four drugs that have been shown to be safe and effective in the treatment of HAE attacks. ${ }^{47,55,82-84}$ Plasmaderived $\mathrm{C} 1-\mathrm{INH}$ and recombinant $\mathrm{C} 1-\mathrm{INH}$ function by replacing deficient or dysfunctional C1-INH. ${ }^{47,55,82-84}$ Ecallantide inhibits plasma kallikrein, and icatibant is a bradykinin $\mathrm{B}_{2}$-receptor antagonist; as such, both antagonize the effects of bradykinin. ${ }^{47,55,82-84}$ Additionally, fresh frozen plasma (FFP) contains $\mathrm{C} 1-\mathrm{INH}$ and has been shown effective in acute HAE attacks, but its use may also result in an exacerbation of the attack. ${ }^{5,47,55,82-84}$ There are no controlled studies proving the

Table 2 Required criteria for a diagnosis of HAE with normal CI-INH (HAE-FXII and HAE-U)

I. A history of recurrent angioedema in the absence of concomitant urticaria or use of a medication known to cause angioedema

2. Documented normal or near-normal C4, CI-INH protein, and $\mathrm{CI}$-INH function

3. One of the following:

a. A demonstrated F/2 mutation associated with the disease

b. A positive family history of angioedema and documented evidence of lack of efficacy of chronic high-dose antihistamine therapy ${ }^{\mathrm{a}}$

Notes: a Cetirizine at $40 \mathrm{mg} / \mathrm{d}$ or the equivalent for at least I month and an interval expected to be associated with 3 or more attacks of angioedema. Data from Zuraw et al. ${ }^{25}$ Abbreviations: $\mathrm{CI}-\mathrm{INH}, \mathrm{Cl}$ esterase inhibitor; HAE-FXII, hereditary angioedema - caused by factor XII; HAE-U, hereditary angioedema - unknown cause. 
efficiency of FFP; therefore, the approved drugs described above should be the first line of treatment in acute episodes, and caution should be exercised when using FFP.

Symptomatic treatment should be considered in addition to on-demand therapy. Moderate-to-severe abdominal pain typically requires analgesics, often in the form of narcotics, as well as antiemetics and occasionally aggressive fluid replacement due to extracellular fluid losses. ${ }^{5,49,69}$ Patients with laryngeal attacks require hospital admission for observation in the event that they require intubation or tracheotomy, which should be discussed as early as possible during any episode. , $^{5,69}$ Importantly, given airway distortion due to angioedema, highly skilled airway management is required to perform the intubation and backup tracheotomy must be available. ${ }^{55,80}$

Experts in the management of gynecologic and obstetric issues with HAE recommend a plasma-derived $\mathrm{C} 1-\mathrm{INH}$ as preferential treatment for acute attacks during pregnancy. ${ }^{29}$ Androgens are contraindicated in pregnancy and no data are available regarding ecallantide or icatibant, which are not currently recommended in pregnancy. ${ }^{29}$

Given its low prevalence, emergency care staff may be unfamiliar with the signs and symptoms of HAE. Therefore, it is recommended that patients always carry with them relevant information about their disease, which may summarize treatment of an acute episode and can aid in communication with emergency care providers. ${ }^{77,81}$ Additionally, when possible, patients may have their treatments for acute attacks administered at home, preferably self-administered, which has been shown to significantly shorten time to resolution and improve quality of life. ${ }^{77,81}$

\section{Short-term prophylaxis}

Short-term prophylaxis is recommended for HAE patients who will be exposed to situations that may result in a known or potential trigger for an angioedema attack, although the efficacy has not been well studied. ${ }^{5}$ These situations include dental work, invasive medical procedures, and surgical procedures. ${ }^{81,85}$ A study showed that facial, upper airway, or laryngeal edema occurred in $21.5 \%$ of tooth extractions without prophylaxis compared to $12.5 \%$ after short-term prophylaxis. ${ }^{86}$ Typical regimens consist of plasma-derived C1-INH given 1 hour prior to the procedure with two doses of on-demand therapy available for postprocedural swelling. For minor procedures, two doses of on-demand therapy may be adequate. ${ }^{81,85}$ Alternatively, when $\mathrm{C} 1$-INH concentrate is not available, androgens can be provided 5 days prior and 3 days after the procedure at a dose of $200 \mathrm{mg}$ three times per day of danazol, but on-demand therapy should also be available. ${ }^{5}$ Due to their short half-life, ecallantide and icatibant should not be used for prophylaxis. ${ }^{87}$ The benefit for short-term prophylaxis using recombinant $\mathrm{C} 1-\mathrm{INH}$ has not been established, although a recent pilot study suggests a reduction of HAE attacks while receiving this therapy. ${ }^{87,88}$ FFP may be used as an alternative to C1-INH when other options are unavailable; approximately $1 \mathrm{cc}$ of FFP contains 1 unit of C1-INH. ${ }^{47,55,82-84}$

\section{Long-term prophylaxis}

Long-term prophylaxis should be considered in HAE patients who, despite optimal access to on-demand therapy and efforts to avoid triggers, continue to experience significant recurrence of attacks or an unacceptable amount of symptoms. ${ }^{80}$ The agents used for long-term prophylaxis are androgens (ie, danazol), antifibrinolytics (ie, aminocaproic acid or tranexamic acid), and C1-INH. Antifibrinolytics have shown limited efficacy, and some consensus guidelines do not recommend them for either long-term prophylaxis or on-demand therapy ${ }^{5,73}$ Long-term prophylaxis with danazol and C1-INH has been shown to prevent recurrence of HAE attacks, but with either medication on-demand therapy is essential since neither provide absolute protection. ${ }^{55}$ Recently, a large cohort study revealed improved outcomes in patients who stopped long-term prophylaxis with danazol or tranexamic acid in favor of on-demand treatment with $\mathrm{C} 1$-INH concentrate or icatibant. $^{89}$

\section{General care in the primary care setting} Education about the illness is crucial in the management of the newly diagnosed HAE patient. Patients can access detailed patient and family-focused resources at "HAEi: the International Patient Organization for C1 Inhibitor Deficiencies" and at the "HAEA: US Hereditary Angioedema Association." 90,91 Patients should be counseled about avoiding possible triggers including avoidance of trauma, particularly in the face and upper respiratory tract, and of certain medications including ACE-inhibitors and estrogen-containing drugs. ${ }^{25,27,30,32}$ Using patient and expert input, an 18-item questionnaire known as HAE PRO has recently been developed as an assessment of HAE attacks and treatment, which may be useful to track progress and outcomes. ${ }^{92}$ It is also recommended that primary care physicians pay particular attention to psychological issues such as depression and anxiety, which may affect over half of HAE patients. ${ }^{58,59,89}$

Baseline laboratory studies are recommended for all HAE patients, including liver function tests, albumin, creatinine kinase, blood urea nitrogen, creatinine, lipid panel, 
complete blood count with differential, pregnancy testing, and urinalysis. To screen for blood-borne infections, HIV, hepatitis B, and hepatitis $\mathrm{C}$ testing should be obtained at baseline given the possible future use of blood products..$^{25,27,30}$ In addition, patients should be vaccinated for hepatitis A and B.

Patients on long-term androgen prophylaxis should repeat liver function, lipid profile, and urinalysis tests every 6 months. ${ }^{25,27,30}$ These patients are also at increased risk for developing liver neoplasms and, as such, some guidelines suggest measurement of $\alpha$-fetoprotein every 6 months as well as liver ultrasound every 6-12 months depending on androgen therapy dosing. ${ }^{25,27,30}$ For patients receiving $\mathrm{C} 1-\mathrm{INH}$ therapy, periodic testing for HIV and hepatitis $\mathrm{B}$ and $\mathrm{C}$ is recommended..$^{25,27,30}$ Patients on antifibrinolytics for long-term prophylaxis must have their dosing adjusted to renal function, and, therefore, yearly blood urea nitrogen and serum creatinine should be measured in addition to creatinine kinase, liver function tests, and urinalysis every 6 months. ${ }^{25,27,30}$

\section{Management of pediatric HAE}

The care of children with HAE is complicated by concern about potential adverse effects of androgens on growth and development, particularly with induction of premature puberty and premature closure of epiphyseal plates. ${ }^{36,73,93}$ Approved options for pediatric therapy are limited, but recent studies support current consensus guidelines that strongly recommend home and self-treatment using plasma derived C1-INH. ${ }^{36,55,73,80,93}$ Recently approved for patients aged 12 and older, ecallantide has reported good efficacy and acceptable safety in patients 9-17 years old. ${ }^{73,94}$ Use of icatibant and recombinant C1-INH has not been well described in the pediatric population, but a pediatric trial of icatibant is in progress..$^{73,95}$

\section{Conclusion}

The most significant hurdle to diagnosis of HAE in the primary care clinic and the emergency department is low initial suspicion. Clinical presentation of the disease, both in the form of cutaneous or submucosal angioedema and abdominal pain, is often confused with other conditions, which may significantly delay diagnosis. ${ }^{31,37-42}$ Family history is positive for similar symptoms in approximately three out of four affected individuals. During an acute episode, virtually all patients have low levels of serum $C 4 .{ }^{50,66-68}$ Regardless of current symptom manifestation, the primary care physician should order tests of serum $\mathrm{C} 4$ and $\mathrm{C} 1$-INH protein and function levels when there is clinical suspicion. In the majority of cases, HAE-1 will return low levels ( $<50 \%$ normal) in all three tests. By contrast, HAE-2 presents with normal C1-INH protein levels, but low $\mathrm{C} 4$ and $\mathrm{C} 1-\mathrm{INH}$ functional levels. Consensus guidelines indicate that these laboratory tests should be repeated 1-3 months later to increase the accuracy of the results. ${ }^{5}$ Importantly, the primary care physician should consult with an HAE expert, who can provide more specialized support for both diagnosis and management.

HAE with normal C1-INH levels is much more challenging to diagnose, and requires a history of recurrent angioedema without urticaria, documented normal or nearnormal C4, C1-INH protein, and C1-INH functional levels, and either a demonstrated $F 12$ mutation or a positive family history (Table 2). ${ }^{25}$

Management of HAE has improved in recent decades with a better understanding of the pathogenesis of the disease and an increased availability of approved treatments, including home therapies. Although not yet a common practice, physicians should attempt to screen for the disease in family members of diagnosed individuals as well as educate them on the autosomal dominant hereditary pattern of the disease. It is recommended that all patients carry information explaining the nature of the disease in case of an acute attack. Furthermore, all patients should have routine follow-up visits and action plans for attacks including access to on-demand emergency therapy. ${ }^{5}$

\section{Disclosure}

Maria Paula Henao, Jennifer Kraschnewski, and Ted Kelbel have no conflicts of interest or financial disclosures. Timothy J Craig does research for CSL Behring, Dyax, and Shire. He speaks for CSL Behring, Dyax, and Shire. He consults with Biocryst. He is also on the Advisory Board of the HAE-A. The authors report no other conflicts of interest in this work.

\section{References}

1. Cicardi M, Agostoni A. Hereditary angioedema. N Engl J Med. 1996; 334(25):1666-1667.

2. Nzeako UC, Frigas E, Tremaine WJ. Hereditary angioedema: a broad review for clinicians. Arch Intern Med. 2001;161(20):2417-2429.

3. Zuraw BL, Christiansen SC. Hereditary angioedema and bradykininmediated angioedema. In: Adkinson NF Jr, Bochner BS, Burks AW, et al, editors. Middleton's Allergy: Principles and Practice. Vol. 1, 8th ed. Philadelphia, PA: Elsevier Saunders; 2014:588-601.

4. Osler W. Landmark publication from The American Journal of the Medical Sciences: hereditary angio-neurotic oedema. 1888. Am J Med Sci. 2010; 339(2): 175-178.

5. Craig T, Aygören-Pürsün E, Bork K, et al. WAO guideline for the management of hereditary angioedema. World Allergy Organ J. 2012; 5(12):182-199.

6. deShazo RD, Frank MM. Genius at work: Osler's 1888 article on hereditary angioedema. Am J Med Sci. 2010;339(2):179-181.

7. Donaldson VH, Evans RR. A biochemical abnormality in hereditary angioneurotic edema. Am J Med. 1963;35(1):37-44. 
8. Landerman NS, Webster ME, Becker EL, Ratcliffe HE. Hereditary angioneurotic edema. II. Deficiency of inhibitor for serum globulin permeability factor and/or plasma kallikrein. J Allergy. 1962;33: 330-341.

9. Rosen FS, Pensky J, Donaldson V, Charache P. Hereditary angioneurotic edema: two genetic variants. Science. 1965;148(3672):957-958

10. Davis AE III. C1 inhibitor and hereditary angioneurotic edema. Annu Rev Immunol. 1988;6:595-628.

11. Johnsrud I, Kulseth MA, Rødningen OK, et al. A nationwide study of Norwegian patients with hereditary angioedema with $\mathrm{C} 1$ inhibitor deficiency identified six novel mutations in SERPING1. PLoS One. 2015; 10(7): 0131637

12. Donaldson VH, Rosen FS, Bing DH. Role of the second component of complement $(\mathrm{C} 2)$ and plasmin in kinin release in hereditary angioneurotic edema (H.A.N.E.) plasma. Trans Assoc Am Physicians. 1977;90: 174-183.

13. Curd JG, Prograis LJ, Cochrane CG. Detection of active kallikrein in induced blister fluids of hereditary angioedema patients. $J$ Exp Med 1980;152(3):742-747.

14. Bowen T, Cicardi M, Bork K, et al. Hereditary angiodema: a current stateof-the-art review, VII: Canadian Hungarian 2007 International Consensus Algorithm for the Diagnosis, Therapy, and Management of Hereditary Angioedema. Ann Allergy Asthma Immunol. 2008;100(1 Suppl 2) S30-S40.

15. Davis AE. Mechanism of angioedema in first complement component inhibitor deficiency. Immunol Allergy Clin North Am. 2006; 26(4):633-651.

16. Bork K, Barnstedt SE, Koch P, Traupe H. Hereditary angioedema with normal C1-inhibitor activity in women. Lancet. 2000;356(9225): 213-217.

17. Bouillet L. Hereditary angioedema in women. Allergy Asthma Clin Immunol. 2010;6:17.

18. Binkley KE, Davis A III. Clinical, biochemical, and genetic characterization of a novel estrogen-dependent inherited form of angioedema. J Allergy Clin Immunol. 2000;106(3):546-550.

19. Dewald G, Bork K. Missense mutations in the coagulation factor XII (Hageman factor) gene in hereditary angioedema with normal $\mathrm{C} 1$ inhibitor. Biochem Biophys Res Commun. 2006;343(4):1286-1289.

20. Charignon D, Ghannam A, Defendi F, et al. Hereditary angioedema with F12 mutation: factors modifying the clinical phenotype. Allergy. 2014;69(12):1659-1665.

21. Kiss N, Barabás E, Várnai K, et al. Novel duplication in the F12 gene in a patient with recurrent angioedema. Clin Immunol. 2013;149. $142-145$.

22. Nagy N, Greaves MW, Tanaka A, McGrath JA, Grattan CE. Recurrent European missense mutation in the F12 gene in a British family with type III hereditary angioedema. J Dermatol Sci. 2009;56:62-64.

23. Zuraw BL, Christiansen SC. Pathophysiology of hereditary angioedema. Am J Rhinol Allergy. 2011;25(6):373-378.

24. Firinu D, Bafunno V, Vecchione G, et al. Characterization of patients with angioedema without wheals: the importance of F12 gene screening. Clin Immunol. 2015;157(2):239-248.

25. Zuraw BL, Bork K, Binkley KE, et al. Hereditary angioedema with normal $\mathrm{C} 1$ inhibitor function: consensus of an international expert panel. Allergy Asthma Proc. 2012;33(Suppl 1):S145-S156.

26. Cicardi M, Aberer W, Banerji A, et al. Classification, diagnosis, and approach to treatment for angioedema: consensus report from the Hereditary Angioedema International Working Group. Allergy. 2014;69(5) 602-616

27. Bowen T, Cicardi M, Farkas H, et al. 2010 International consensus algorithm for the diagnosis, therapy and management of hereditary angioedema. Allergy Asthma Clin Immunol. 2010;6:24.

28. Caballero T, Baeza ML, Cabañas R, et al. Consensus statement on the diagnosis, management, and treatment of angioedema mediated by bradykinin. Part I. Classification, epidemiology, pathophysiology, genetics, clinical symptoms, and diagnosis. J Investig Allergol Clin Immunol. 2011;21(5):333-347.
29. Caballero T, Farkas H, Bouillet L, et al. International consensus and practical guidelines on the gynecologic and obstetric management of female patients with hereditary angioedema caused by $\mathrm{C} 1$ inhibitor deficiency. J Allergy Clin Immunol. 2012;129(2):308-320.

30. Cicardi M, Bork K, Caballero T, et al. Evidence-based recommendations for the therapeutic management of angioedema owing to hereditary $\mathrm{C} 1$ inhibitor deficiency: consensus report of an International Working Group. Allergy. 2012;67(2):147-157.

31. Lunn ML, Santos CB, Craig TJ. Is there a need for clinical guidelines in the United States for the diagnosis of hereditary angioedema and the screening of family members of affected patients? Ann Allergy Asthma Immunol. 2010;104(3):211-214.

32. Gompels MM, Lock RJ, Abinun M, et al. C1 inhibitor deficiency: consensus document. Clin Exp Immunol. 2005;139(3):379-394.

33. Longhurst HJ, Farkas H, Craig T, et al. HAE international home therapy consensus document. Allergy Asthma Clin Immunol. 2010;6:22.

34. Moellman JJ, Bernstein JA, Lindsell C, et al. A consensus parameter for the evaluation and management of angioedema in the emergency department. Acad Emerg Med. 2014;21(4):469-484.

35. Riedl M. Hereditary angioedema therapies in the United States: movement toward an international treatment consensus. Clin Ther. 2012;34(3): 623-630.

36. Wahn V, Aberer W, Eberl W, et al. Hereditary angioedema (HAE) in children and adolescents - a consensus on therapeutic strategies. Eur J Pediatr. 2012;171(9):1339-1348.

37. Bhardwaj N, Craig TJ. Treatment of hereditary angioedema: a review (CME). Transfusion. 2014;54(11):2989-2996; quiz 2988.

38. Patel N, Suarez LD, Kapur S, Bielory L. Hereditary angioedema and gastrointestinal complications: an extensive review of the literature. Case Reports Immunol. 2015;2015:925861.

39. Longhurst H, Cicardi M. Hereditary angio-oedema. Lancet. 2012; 379(9814):474-481.

40. Xu Y-Y, Buyantseva LV, Agarwal NS, Olivieri K, Zhi Y-X, Craig TJ. Update on treatment of hereditary angioedema. Clin Exp Allergy. 2013; 43(4):395-405.

41. Roche O, Blanch A, Caballero T, Sastre N, Callejo D, López-Trascasa M. Hereditary angioedema due to $\mathrm{C} 1$ inhibitor deficiency: patient registry and approach to the prevalence in Spain. Ann Allergy Asthma Immunol. 2005;94(4):498-503.

42. Zanichelli A, Magerl M, Longhurst H, Fabien V, Maurer M. Hereditary angioedema with $\mathrm{C} 1$ inhibitor deficiency: delay in diagnosis in Europe. Allergy Asthma Clin Immunol. 2013;9:29.

43. Bork K, Hardt J, Witzke G. Fatal laryngeal attacks and mortality in hereditary angioedema due to C1-INH deficiency. J Allergy Clin Immunol. 2012;130(3):692-697.

44. Xu Y-Y, Jiang Y, Zhi Y-X, et al. Clinical features of hereditary angioedema in Chinese patients: new findings and differences from other populations. Eur J Dermatol. 2013;23(4):500-504.

45. Bork K, Meng G, Staubach P, Hardt J. Hereditary angioedema: new findings concerning symptoms, affected organs, and course. Am JMed. 2006;119(3):267-274.

46. Tachdjian R, Banerji A, Guyer A, Morphew T. Current characteristics associated with hereditary angioedema attacks and treatment: the home infusion based patient experience. Allergy Asthma Proc. 2015;36(2): $151-159$.

47. Lumry WR. Overview of epidemiology, pathophysiology, and disease progression in hereditary angioedema. Am J Manag Care. 2013; 19(7 Suppl):S103-S110.

48. Khan DA. Hereditary angioedema: historical aspects, classification, pathophysiology, clinical presentation, and laboratory diagnosis. Allergy Asthma Proc. 2011;32:1-10.

49. Frank MM, Gelfand JA, Atkinson JP. Hereditary angioedema: the clinical syndrome and its management. Ann Intern Med. 1976;84(5): 580-593.

50. Agostoni A, Cicardi M. Hereditary and acquired C1-inhibitor deficiency: biological and clinical characteristics in 235 patients. Medicine (Baltimore). 1992;71(4):206-215. 
51. Nzeako UC, Longhurst HJ. Many faces of angioedema: focus on the diagnosis and management of abdominal manifestations of hereditary angioedema. Eur J Gastroenterol Hepatol. 2012;24(4):353-361.

52. Koruth JS, Eckardt AJ, Levey JM. Hereditary angioedema involving the colon: endoscopic appearance and review of GI manifestations. Gastrointest Endosc. 2005;61(7):907-911.

53. Cohen N, Sharon A, Golik A, Zaidenstein R, Modai D. Hereditary angioneurotic edema with severe hypovolemic shock. J Clin Gastroenterol. 1993;16(3):237-239.

54. Bork K, Staubach P, Eckardt AJ, Hardt J. Symptoms, course, and complications of abdominal attacks in hereditary angioedema due to C1 inhibitor deficiency. Am J Gastroenterol. 2006;101(3):619-627.

55. Zuraw BL. Clinical practice. Hereditary angioedema. $N$ Engl J Med. 2008;359(10):1027-1036.

56. Farkas H. Pediatric hereditary angioedema due to $\mathrm{C} 1$-inhibitor deficiency. Allergy Asthma Clin Immunol. 2010;6:18.

57. Prematta MJ, Kemp JG, Gibbs JG, Mende C, Rhoads C, Craig TJ. Frequency, timing, and type of prodromal symptoms associated with hereditary angioedema attacks. Allergy Asthma Proc. 2009;30(5): 506-511.

58. Salemi M, Bella FD, Miragliotta A, et al. Psychological correlates in subjects with hereditary angioedema (HAE). J Psychol Psychother. 2014;4:134.

59. Fouche AS, Saunders EFH, Craig T. Depression and anxiety in patients with hereditary angioedema. Ann Allergy Asthma Immunol. 2014; 112(4):371-375.

60. Lumry WR, Castaldo AJ, Vernon MK, Blaustein MB, Wilson DA, Horn PT. The humanistic burden of hereditary angioedema: impact on health-related quality of life, productivity, and depression. Allergy Asthma Proc. 2010;31(5):407-414.

61. Ohsawa I, Nagamachi S, Suzuki H, et al. Leukocytosis and high hematocrit levels during abdominal attacks of hereditary angioedema. BMC Gastroenterol. 2013;13:123.

62. Calbo L, Quattrocchi P, Ferlazzo B. Abdominal attack of hereditary angioedema associated with marked leucocytosis. A case report. Ital J Gastroenterol. 1992;24(8):464-465.

63. Gakhal MS, Marcotte GV. Hereditary angioedema: imaging manifestations and clinical management. Emerg Radiol. 2015;22:83-90.

64. Jalaj S, Scolapio JS. Gastrointestinal manifestations, diagnosis, and management of hereditary angioedema. J Clin Gastroenterol. 2013; 47(10):817-823.

65. De Backer AI, De Schepper AM, Vandevenne JE, Schoeters P, Michielsen P, Stevens WJ. CT of angioedema of the small bowel. AJR Am J Roentgenol. 2001;176(3):649-652.

66. Joseph K, Bains S, Tholanikunnel BG, et al. A novel assay to diagnose hereditary angioedema utilizing inhibition of bradykinin-forming enzymes. Allergy. 2015;70:115-119.

67. Tarzi MD, Hickey A, Förster T, Mohammadi M, Longhurst HJ. An evaluation of tests used for the diagnosis and monitoring of $\mathrm{C} 1$ inhibitor deficiency: normal serum $\mathrm{C} 4$ does not exclude hereditary angio-oedema. Clin Exp Immunol. 2007;149(3):513-516.

68. Agostoni A, Aygören-Pürsün E, Binkley KE, et al. Hereditary and acquired angioedema: problems and progress: proceedings of the third $\mathrm{C} 1$ esterase inhibitor deficiency workshop and beyond. J Allergy Clin Immunol. 2004;114(3 Supp1):S51-S131.

69. Karim Y, Griffiths H, Deacock S. Normal complement C4 values do not exclude hereditary angioedema. J Clin Pathol. 2004;57(2): 213-214.

70. Gompels MM, Lock RJ, Morgan JE, Osborne J, Brown A, Virgo PF. A multicentre evaluation of the diagnostic efficiency of serological investigations for $\mathrm{C} 1$ inhibitor deficiency. J Clin Pathol. 2002;55(2): 145-147.

71. Cacoub P, Frémeaux-Bacchi V, De Lacroix I, et al. A new type of acquired $\mathrm{C} 1$ inhibitor deficiency associated with systemic lupus erythematosus. Arthritis Rheum. 2001;44(8):1836-1840.
72. Khan S, Tarzi MD, Doré PC, Sewell WA, Longhurst HJ. Secondary systemic lupus erythematosus: an analysis of 4 cases of uncontrolled hereditary angioedema. Clin Immunol. 2007;123(1):14-17.

73. Craig TJ, Schneider LC, MacGinnitie AJ. Plasma-derived C1-INH for managing hereditary angioedema in pediatric patients: a systematic review. Pediatr Allergy Immunol. 2015;26(6):537-544.

74. Johnston DT. Diagnosis and management of hereditary angioedema. J Am Osteopath Assoc. 2011;111(1):28-36.

75. Gompels MM, Lock RJ, Unsworth DJ, Johnston SL, Archer CB, Davies SV. Misdiagnosis of hereditary angio-oedema type 1 and type 2. Br J Dermatol. 2003;148(4):719-723.

76. Wagenaar-Bos IGA, Drouet C, Aygören-Pursun E, et al. Functional C1-inhibitor diagnostics in hereditary angioedema: assay evaluation and recommendations. J Immunol Methods. 2008;338(1-2):14-20.

77. Bork K. An evidence based therapeutic approach to hereditary and acquired angioedema. Curr Opin Allergy Clin Immunol. 2014;14(4): 354-362.

78. Craig TJ, Bernstein JA, Farkas H, Bouillet L, Boccon-Gibod I. Diagnosis and treatment of bradykinin-mediated angioedema: outcomes from an angioedema expert consensus meeting. Int Arch Allergy Immunol. 2014;165(2):119-127.

79. Bowen T, Brosz J, Brosz K, Hebert J, Ritchie B. Management of hereditary angioedema: 2010 Canadian approach. Allergy Asthma Clin Immunol. 2010;6:20.

80. Zuraw BL, Bernstein JA, Lang DM, et al. A focused parameter update: hereditary angioedema, acquired $\mathrm{C} 1$ inhibitor deficiency, and angiotensin-converting enzyme inhibitor-associated angioedema. J Allergy Clin Immunol. 2013;131(6):1491-1493.

81. Zuraw BL, Banerji A, Bernstein JA, et al. US Hereditary Angioedema Association Medical Advisory Board 2013 recommendations for the management of hereditary angioedema due to $\mathrm{C} 1$ inhibitor deficiency. J Allergy Clin Immunol Pract. 2013;1(5):458-467.

82. Craig TJ, Levy RJ, Wasserman RL, et al. Efficacy of human C1 esterase inhibitor concentrate compared with placebo in acute hereditary angioedema attacks. J Allergy Clin Immunol. 2009;124(4):801-808.

83. Zuraw BL, Busse PJ, White M, et al. Nanofiltered C1 inhibitor concentrate for treatment of hereditary angioedema. N Engl J Med. 2010;363(6): 513-522.

84. Cicardi M, Banerji A, Bracho F, et al. Icatibant, a new bradykininreceptor antagonist, in hereditary angioedema. N Engl J Med. 2010; 363(6):532-541.

85. Farkas H, Zotter Z, Csuka D, et al. Short-term prophylaxis in hereditary angioedema due to deficiency of the $\mathrm{C} 1$-inhibitor - a long-term survey. Allergy. 2012;67(12):1586-1593.

86. Bork K, Hardt J, Staubach-Renz P, Witzke G. Risk of laryngeal edema and facial swellings after tooth extraction in patients with hereditary angioedema with and without prophylaxis with $\mathrm{C} 1$ inhibitor concentrate: a retrospective study. Oral Surg Oral Med Oral Pathol Oral Radiol Endod. 2011;112(1):58-64.

87. Sabharwal G, Craig T. Recombinant human $\mathrm{C} 1$ esterase inhibitor for the treatment of hereditary angioedema due to $\mathrm{C} 1$ inhibitor deficiency (C1-INH-HAE). Expert Rev Clin Immunol. 2015;11(3):319-327.

88. Riedl M. Recombinant human $\mathrm{C} 1$ esterase inhibitor in the management of hereditary angioedema. Clin Drug Investig. 2015;35(7): 407-417.

89. Bygum A. Hereditary angioedema - consequences of a new treatment paradigm in Denmark. Acta Derm Venereol. 2014;94(4):436-441.

90. HAEi: International Patient Organization for $\mathrm{C} 1$ Inhibitor Deficiencies. Available from: http://haei.org/. Accessed October 29, 2015.

91. HAEA: US Hereditary Angioedema Association. Available from: https://www.haea.org/. Accessed October 29, 2015.

92. Bonner N, Abetz-Webb L, Renault L, et al. Development and content validity testing of a patient-reported outcomes questionnaire for the assessment of hereditary angioedema in observational studies. Health Qual Life Outcomes. 2015;13:92. 
93. Farkas H, Varga L, Széplaki G, Visy B, Harmat G, Bowen T. Management of hereditary angioedema in pediatric patients. Pediatrics. 2007; 120(3):e713-e722.

94. MacGinnitie AJ, Davis-Lorton M, Stolz LE, Tachdjian R. Use of ecallantide in pediatric hereditary angioedema. Pediatrics. 2013;132(2): e490-e497.
95. Aggarwal V. A Pharmacokinetic, Tolerability and Safety Study of Icatibant in Children and Adolescents With Hereditary Angioedema. Bethesda, MD: U.S. National Library of Medicine. Available from: https://clinicaltrials.gov/show/NCT01386658. NLM Identifier: NCT01386658. Accessed January 12, 2016.

\section{Publish your work in this journal}

Therapeutics and Clinical Risk Management is an international, peerreviewed journal of clinical therapeutics and risk management, focusing on concise rapid reporting of clinical studies in all therapeutic areas, outcomes, safety, and programs for the effective, safe, and sustained use of medicines. This journal is indexed on PubMed Central, CAS,
EMBase, Scopus and the Elsevier Bibliographic databases. The manuscript management system is completely online and includes a very quick and fair peer-review system, which is all easy to use. Visit http://www.dovepress.com/testimonials.php to read real quotes from published authors.

Submit your manuscript here: http://www.dovepress.com/therapeutics-and-clinical-risk-management-journal 